\title{
SELECTION OF REINFORCING PHASES FOR ALUMINUM MATRIX COMPOSITES USING THERMODYNAMIC STABILITY CRITERION
}

\author{
${ }^{1}$ Evgeny PRUSOV, ${ }^{2}$ Vladislav DEEV, ${ }^{1}$ Vladimir KECHIN \\ ${ }^{1}$ Vladimir State University named after Alexander and Nikolay Stoletovs, Vladimir, Russian Federation, \\ eprusov@mail.ru \\ ${ }^{2}$ National University of Science \& Technology MISIS, Moscow, Russian Federation, \\ deev.vb@mail.ru
}

https://doi.org/10.37904/metal.2020.3609

\begin{abstract}
A significant number of reinforcing components are currently available for the manufacture of aluminum matrix composites. The justified selection of reinforcement determines not only the working capacity of the created composite materials under various operating conditions, but also the fundamental possibility of obtaining the composites by liquid-phase methods. The issues of thermodynamic compatibility of components are crucial in the design of aluminum matrix composites and cast products from them for specified operating conditions, as well as in the development of technological processes for their production. To assess the thermodynamic stability of compounds potentially suitable for reinforcing the aluminum matrix composites, distribution diagrams were constructed in the coordinates "formation enthalpy - melting temperature". The initial data for the criterial analysis were collected from a wide range of sources and verified by comparing the values given by various researchers. According to thermodynamic stability criterion, the compounds distribution was carried out using carbides as an example. All compounds were divided into three groups: refractory thermodynamically stable (I), refractory thermodynamically unstable (II) and fusible (III). It was shown that preference should be given to compounds that are located in the group I. For the selected carbides, the thermodynamic probability of their interaction with the matrix melt was estimated, and the temperature ranges were determined in which the corresponding interfacial interaction reactions can occur spontaneously. According to the analysis, the nomenclature of carbide phases that are potentially stable in the aluminum melt was determined.
\end{abstract}

Keywords: Aluminum matrix composites, reinforcing phases, liquid-phase technologies, thermodynamic stability

\section{INTRODUCTION}

Cast aluminum matrix composites are an effective alternative to traditional alloys for structural and functional applications, and are promising for use in the production of a wide range of parts in various sectors of modern industry [1-3]. The creation of such materials is based on the adding of refractory compounds of the second phase (carbides, borides, nitrides, etc.) into the metal base (matrix), which leads to a qualitatively new level of mechanical and operational properties [4-6]. However, the development of new aluminum matrix composites over the past decades has mainly been carried out in a consistent way through experimental trials and errors primarily based on the intuition of researchers and accumulated experience $[7,8]$.

At the same time, the traditional intuitively empirical approach to the search for new components and compositions of materials has obvious limitations in assessing the entire range of potential combinations of components, and is associated with significant time expenses and material resources $[9,10]$. Thus, a 
sequential experimental search of suitable combinations of a matrix and a reinforcement for only one type of reinforcing phase or matrix alloy will entail the need to obtain and study many thousands of compositions, which makes it practically impossible. In this regard, to select the composition of the matrix and the reinforcing phases, it is advisable to apply a criteria-based approach that allows filtering out obviously incompatible or undesirable components [11]. Since aluminum matrix composites consist of heterogeneous components, the issues of chemical and physical compatibility of these components are crucial in the design of composites and products from them taking into account operating conditions, as well as in the development of technological processes for their production [12-14]. In this regard, the screening of components requires the development of reliable and adequate criteria, allowing to take into account the contribution of various components to the required level of a particular property, as well as the compatibility of the matrix and potential reinforcing phases. One of such criteria is thermodynamic stability, which should be evaluated both for standard conditions and under conditions of possible interaction with the matrix melt in a wide temperature range.

The aim of this work is an analytical assessment of the thermodynamic stability of compounds (by the case of carbides) for the selection of reinforcing phases in the production of aluminum matrix composites by metallurgical methods.

\section{METHODS}

The formation of the desired structural and morphological parameters of aluminum matrix composites and the corresponding level of their physical-mechanical and operational properties will be largely determined by the thermodynamic properties of the matrix material and the reinforcing components used. In particular, at the selection of the reinforcing phases, one should take into account their thermodynamic stability, which is determined by the standard enthalpy of formation of compounds and their melting temperature.

It is proposed to carry out a criterion-based selection of components of cast aluminum matrix composites taking into account their thermodynamic stability by means of the materials selection charts. Effective design of composites requires reliable data on the properties of the metal matrix and reinforcing compounds. There are no universal databases on the properties of reinforcing particles and matrix materials, which to some extent complicates the search for components. In this regard, the initial data for the criteria analysis was collected from a wide range of sources and verified by comparing the values given by various researchers. To search for the data, electronic databases on the thermodynamic properties of compounds and simple substances were used, including NIST Chemistry WebBook, NASA ThermoBuild, and SpringerMaterials.

For the compounds, selected on the basis of predictive calculations, it is necessary to evaluate the processes of interfacial interaction with the matrix, which will allow to determine the list of compositions recommended for use in the production of aluminum matrix composites by the metallurgical methods. At this stage, we used the method of thermodynamic analysis for prediction of the phase constituents interaction with each other and with the matrix alloy. To carry out the analysis, the change in Gibbs free energy during chemical reactions in a given temperature range was calculated using the known relationships of chemical thermodynamics:

$$
\begin{aligned}
& \Delta G_{T}^{0}=\Delta H_{T}^{0}-T \Delta S_{T}^{0} \\
& \Delta H_{T}^{0}=\Delta H_{298}^{0}+\int_{298}^{T} \Delta c_{p} d T \\
& \Delta S_{T}^{0}=\Delta S_{298}^{0}+\int_{298}^{T} \frac{\Delta c_{p}}{T} d T
\end{aligned}
$$


where:

$\Delta H^{0} T, \Delta S^{0} T$ - the change in the enthalpy and entropy of the system at temperature $T$, respectively

$\Delta H^{0}{ }_{298}, \Delta S^{0}{ }_{298}$ - change in the enthalpy and entropy of the system under standard conditions, respectively

$\Delta c_{p}$ - change in heat capacity of the system during the reaction

In the calculations, the following typical schemes of the potential interaction between aluminum and carbide phases were considered (taking into account the availability of initial data on the thermodynamic properties of the corresponding substances):

$$
\begin{aligned}
& \mathrm{Al}+\mathrm{MeC} \rightarrow \mathrm{Al}_{x} \mathrm{C}_{y}+\mathrm{Me} \\
& \mathrm{Al}+\mathrm{MeC} \rightarrow \mathrm{Al}_{x} \mathrm{Me}_{y}+\mathrm{C} \\
& \mathrm{Al}+\mathrm{MeC} \rightarrow \mathrm{Al}_{x} \mathrm{Me}_{y}+\mathrm{Al}_{x} \mathrm{C}_{y}
\end{aligned}
$$

where Me - any metal of the Mendeleev's periodic system of chemical elements.

\section{RESULTS AND DISCUSSION}

Figure 1 shows a diagram for the selection of reinforcing compounds according to the criterion of thermodynamic stability. Negative values of the enthalpy of formation $\left(-\Delta_{f} H^{0}, \mathrm{~kJ} / \mathrm{mol}\right)$ are plotted along the vertical axis, and melting points of the compounds along the horizontal axis.

The standard enthalpy of formation is a fundamental thermodynamic property that determines the phase stability of a compound [15]. The analysis took into account that the more negative $\Delta_{f} H^{\circ}$ values, the higher the stability of the compound with respect to its decomposition into simple substances. Compounds having $\Delta_{f} H^{0}>0$ are unstable and are prone to decomposition. In addition, small negative $\Delta_{f} H^{0}$ values (as a rule, up to $-50 \mathrm{~kJ} / \mathrm{mol}$ ) also correspond to compounds with low thermodynamic stability. The values of the standard enthalpies of compound formation can be used not only to compare the stability of the compound and the simple substances that formed it, but also to compare the stability of various compounds with each other.

Obviously, in the most general case, particles should not have a melting temperature lower than that of a matrix melt. Technological ranges of superheat and temperature-time processing of melts, as a rule, do not exceed $1000{ }^{\circ} \mathrm{C}$ for aluminum alloys $[16,17]$. This value was taken as a basis for selection the lower limit of the melting temperature of compounds potentially suitable for reinforcing the cast aluminum matrix composites. According to the thermodynamic stability criterion, it is possible to distribute all compounds into three groups:

$$
\begin{aligned}
& \text { I. refractory thermodynamically stable }\left(-\Delta_{f} H^{0} \geq 50 \mathrm{~kJ} / \mathrm{mol}, T_{m} \geq 1000^{\circ} \mathrm{C}\right) \text {; } \\
& \text { II. refractory thermodynamically unstable }\left(-\Delta_{f} H^{0}<50 \mathrm{~kJ} / \mathrm{mol}, T_{m} \geq 1000^{\circ} \mathrm{C}\right) \text {; } \\
& \text { III. fusible }\left(T_{m}<100{ }^{\circ} \mathrm{C}\right) \text {. }
\end{aligned}
$$

Moreover, compounds of group I can be divided from the standpoint of suitability for reinforcing into the most favourable (subgroup IA) and favourable (subgroup IB), taking into account the traditional definition of refractoriness by G.V. Samsonov, who classified compounds with a melting point above $1500{ }^{\circ} \mathrm{C}$ as refractory [18]. Thus, the division into subgroups is carried out depending on the value of the melting point of the compound:

subgroup IA - over $1500^{\circ} \mathrm{C}$ (refractory compounds);

subgroup IB - from 1000 to $1500^{\circ} \mathrm{C}$ (heat-resistant compounds). 


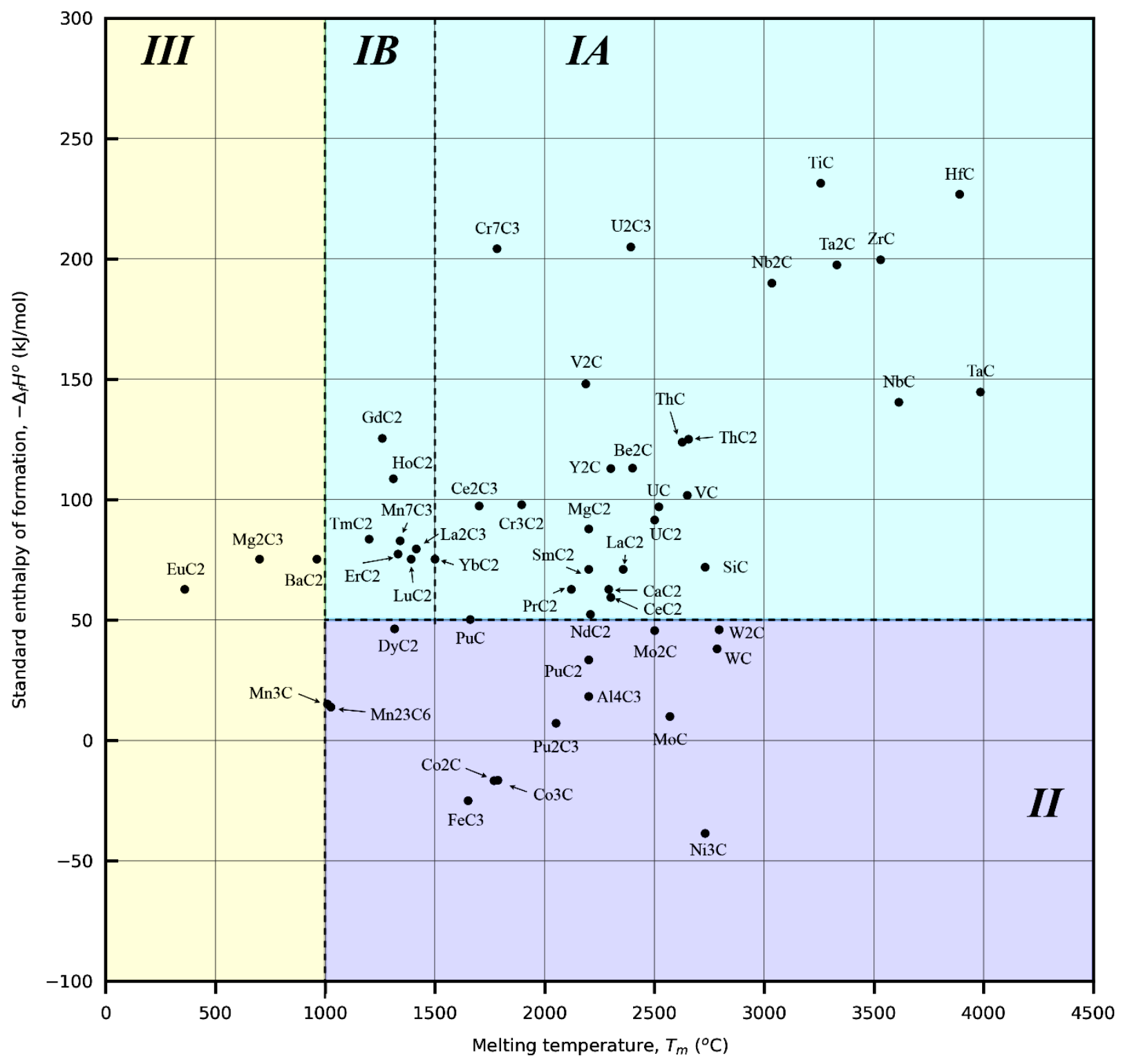

Figure 1 Carbides distribution diagram by the thermodynamic stability criterion

Compounds of groups II and III in terms of thermodynamic stability are recognized as unfavorable for use as reinforcing particles in the production of aluminum matrix composites by metallurgical methods.

For further analysis, the chemical stability of compounds from groups IA and IB in the molten aluminum matrix was evaluated. The calculated values of the Gibbs free energy change $\Delta G$ for the reactions of some selected carbides with liquid aluminum at various temperatures are presented in Table 1. It was taken into account that for reinforcing components, the condition of chemical stability in the matrix melt is the absence of intense interaction with the melt in a technologically significant range of temperatures $\left(700-1000{ }^{\circ} \mathrm{C}\right.$ for aluminum melts).

According to the results of preliminary selection, taking into account the proposed requirements for thermodynamic stability, it can be assumed that compounds of groups IA and IB (see Figure 1) having positive values of the Gibbs free energy change for all interaction variants can be stable in an aluminum melt in the temperature range considered. For example, transition metal carbides ( $\mathrm{TiC}, \mathrm{NbC}, \mathrm{HfC}, \mathrm{ZrC}$ and others) can be classified as such compounds. Certainly, the analysis carried out is far from exhaustive, since it is largely 
limited by the availability of initial data on the thermodynamic properties of different compounds, but it allows us to outline potential areas for further experimental studies in order to accelerate the design of aluminum matrix composites for given operating conditions. Of course, the selection of reinforcing components according to only one criterion cannot be fully justified; for the selection, a wide range of characteristics of compounds, such as density, hardness, elastic modulus, cost, availability for commercial use, and many others, should be taken into account.

Table 1 Gibbs free energy change at the interaction of some selected carbides with aluminum melt

\begin{tabular}{|c|c|c|c|c|}
\hline \multirow{2}{*}{ Carbide } & \multirow{2}{*}{$\begin{array}{l}\text { Predicted reaction } \\
\text { products }\end{array}$} & \multicolumn{3}{|c|}{ Free Gibbs energy $\Delta G(\mathrm{~kJ} / \mathrm{mol})$} \\
\hline & & $700^{\circ} \mathrm{C}$ & $850^{\circ} \mathrm{C}$ & $1000^{\circ} \mathrm{C}$ \\
\hline $\mathrm{Be}_{2} \mathrm{C}$ & $\mathrm{Al}_{4} \mathrm{C}_{3}, \mathrm{Be}$ & 137.61 & 136.51 & 135.09 \\
\hline \multirow[t]{4}{*}{$\mathrm{CaC} 2$} & $\mathrm{Al}_{4} \mathrm{C}_{3}, \mathrm{Ca}$ & 138.66 & 182.59 & 229.73 \\
\hline & $\mathrm{Al}_{4} \mathrm{Ca}, \mathrm{C}$ & 5.80 & 40.79 & 80.94 \\
\hline & $\mathrm{Al}_{2} \mathrm{Ca}, \mathrm{Al}_{4} \mathrm{C}_{3}$ & -542.47 & -514.18 & -483.81 \\
\hline & $\mathrm{Al}_{4} \mathrm{Ca}, \mathrm{Al}_{4} \mathrm{C}_{3}$ & -345.09 & -336.87 & -328.89 \\
\hline \multirow[t]{3}{*}{$\mathrm{Ce}_{2} \mathrm{C}_{3}$} & $\mathrm{Al}_{4} \mathrm{C}_{3}, \mathrm{Ce}$ & 212.24 & 247.76 & 288.77 \\
\hline & $\mathrm{Al}_{4} \mathrm{C}_{3}, \mathrm{Al}_{4} \mathrm{Ce}$ & -205.48 & -214.29 & -221.99 \\
\hline & $\mathrm{Al}_{2} \mathrm{Ce}, \mathrm{C}$ & 142.90 & 199.33 & 263.55 \\
\hline $\mathrm{Cr}_{3} \mathrm{C}_{2}$ & $\mathrm{Al}_{4} \mathrm{C}_{3}, \mathrm{Cr}$ & -578.01 & -779.26 & -1002.76 \\
\hline $\mathrm{Cr}_{7} \mathrm{C}_{3}$ & $\mathrm{Al}_{4} \mathrm{C}_{3}, \mathrm{Cr}$ & -387.44 & -554.20 & -739.76 \\
\hline $\mathrm{HfC}$ & $\mathrm{Al}_{4} \mathrm{C}_{3}, \mathrm{Hf}$ & 497.61 & 505.59 & 515.00 \\
\hline $\mathrm{La}_{2} \mathrm{C}_{3}$ & $\mathrm{Al}_{4} \mathrm{La}, \mathrm{Al}_{4} \mathrm{C}_{3}$ & -167.28 & -175.14 & -182.53 \\
\hline $\mathrm{LaC}_{2}$ & $\mathrm{Al}_{4} \mathrm{C}_{3}, \mathrm{La}$ & -169.03 & -166.26 & -163.21 \\
\hline \multirow[t]{2}{*}{$\mathrm{Mn}_{7} \mathrm{C}_{3}$} & $\mathrm{Al}_{4} \mathrm{C}_{3}, \mathrm{Mn}$ & -549.08 & -735.77 & -947.32 \\
\hline & $\mathrm{Al}_{6} \mathrm{Mn}, \mathrm{C}$ & -236.73 & -183.57 & -129.75 \\
\hline $\mathrm{NbC}$ & $\mathrm{Al}_{4} \mathrm{C}_{3}, \mathrm{Nb}$ & 28.20 & 29.01 & 30.23 \\
\hline $\mathrm{TaC}$ & $\mathrm{Al}_{4} \mathrm{C}_{3}, \mathrm{Ta}$ & 229.21 & 226.37 & 223.86 \\
\hline \multirow[t]{3}{*}{$\mathrm{TiC}$} & $\mathrm{Al}_{4} \mathrm{C}_{3}, \mathrm{Ti}$ & 495.38 & 498.66 & 502.45 \\
\hline & $\mathrm{Al}_{3} \mathrm{Ti}, \mathrm{C}$ & 129.04 & 144.88 & 162.67 \\
\hline & $\mathrm{Al}_{3} \mathrm{Ti}_{1} \mathrm{Al}_{4} \mathrm{C}_{3}$ & 11.03 & -18.68 & -51.86 \\
\hline $\mathrm{ZrC}$ & $\mathrm{Al}_{4} \mathrm{C}_{3}, \mathrm{Zr}$ & 403.44 & 408.00 & 413.44 \\
\hline
\end{tabular}

\section{CONCLUSION}

The thermodynamic stability of various carbide phases was estimated by constructing distribution diagrams in the coordinates "formation enthalpy - melting temperature". For the selected carbides, the thermodynamic probability of interaction with the matrix melt was assessed, and the temperature ranges were determined in which the corresponding interfacial reactions can occur spontaneously. The results obtained can be useful in determining the nomenclature of carbide phases that are potentially stable in the aluminum melt, which allows recommend them for use as reinforcing phases in the production of cast aluminum matrix composites.

\section{ACKNOWLEDGEMENTS}

The reported study was funded by RFBR, project number 20-08-01169. 


\section{REFERENCES}

[1] SUTHAR, J., PATEL, K.M. Processing issues, machining, and applications of aluminum metal matrix composites. Materials and Manufacturing Processes. 2018, vol. 33, no. 5, pp. 499-527.

[2] PANFILOV, A., PRUSOV, E. Current state and trends of development of aluminum matrix composite alloys. In METAL 2013: 22nd International Conference on Metallurgy and Materials. Ostrava: TANGER, 2013, pp. 11951199.

[3] GARG, P., JAMWAL, A., KUMAR, D., SADASIVUNI, K.K., HUSSAIN, C.M., GUPTA, P. Advance research progresses in aluminium matrix composites: manufacturing \& applications. Journal of Materials Research and Technology. 2019, vol. 8, no. 5, pp. 4924-4939.

[4] RAHMAN M.H., AL RASHED, H.M.M. Characterization of silicon carbide reinforced aluminum matrix composites. Procedia Engineering. 2014, vol. 90, pp. 103-109.

[5] SAVAŞ, Ö., KAYIKCI, R. Production and wear properties of metal matrix composites reinforced with boride particles. Materials \& Design. 2013, vol. 51, pp. 641-647.

[6] FALE, S., LIKHITE, A., BHATT, J. Compressive, tensile and wear behavior of ex situ Al/AIN metal matrix composites. Journal of Composite Materials. 2015, vol. 49, no. 16, pp. 1917-1928.

[7] SINGH, J., CHAUHAN, A. Characterization of hybrid aluminum matrix composites for advanced applications - A review. Journal of Materials Research and Technology. 2016, vol. 5, no. 2, pp. 159-169.

[8] SEKAR, K., VASANTHAKUMAR, P. Mechanical properties of Al-Cu alloy metal matrix composite reinforced with $\mathrm{B}_{4} \mathrm{C}$, graphite and wear rate modeling by Taguchi method. Materials Today: Proceedings. 2019, vol. 18, part 7, pp. 3150-3159.

[9] DE PABLO, J.J., JONES, B., KOVACS, C.L., OZOLINS, V., RAMIREZ, A.P. The materials genome initiative, the interplay of experiment, theory and computation. Current Opinion in Solid State and Materials Science. 2014, vol. 18, no. 2, pp. 99-117.

[10] BANERJEE, D., WILLIAMS, J.C. Materials and engineering: an evolving landscape. MRS Bulletin. 2015, vol. 40, pp. 999-1008.

[11] PRUSOV, E., KECHIN, V. General concept of cast metal matrix composites design. In 73rd World Foundry Congress "Creative Foundry". Krakow, 2018, pp. 199-200.

[12] PAIA, B.C., RAVI, K.R., PILLAI, R.M. Role of matrix alloy chemistry on the interfacial reaction and solidification of metal matrix composites. Transactions of the Indian Institute of Metals. 2009, vol. 62, pp. 373-378.

[13] IBRAHIM, M.F., AMMAR, H.R., SAMUEL, A.M., SOLIMAN, M.S., SAMUEL, F.H. Metallurgical parameters controlling matrix/ $\mathrm{B}_{4} \mathrm{C}$ particulate interaction in aluminium-boron carbide metal matrix composites. International Journal of Cast Metals Research. 2013, vol. 26, no. 6, pp. 364-373.

[14] PRUSOV, E., DEEV, V., RAKHUBA, E. Aluminum matrix in-situ composites reinforced with $\mathrm{Mg}_{2} \mathrm{Si}_{\text {and }} \mathrm{Al}_{3} \mathrm{Ti}$. Materials Today: Proceedings. 2019, vol. 11, pp. 386-391.

[15] KIM, G., MESCHEL, S., NASH, P., CHEN, W. Experimental formation enthalpies for intermetallic phases and other inorganic compounds. Scientific Data. 2017, vol. 4, article no. 170162.

[16] CHEN, Z., JIE, W., ZHANG, R. Superheat treatment of Al-7Si-0.55Mg alloy melt. Materials Letters. 2005, vol. 59, no. 17 , pp. 2183-2185.

[17] LI, Q.L., XIA, T.D., LAN, Y.F., LI, P.F. Effects of melt superheat treatment on microstructure and wear behaviours of hypereutectic Al-20Si alloy. Materials Science and Technology. 2014, vol. 30, no. 7, pp. 835-841.

[18] SAMSONOV, G.V., VINITSKIY, I.M. Tugoplavkiye soedineniya: Spravochnik (Refractory compounds: $A$ handbook). Moscow: Metallurgiya, 1976. (In Russian) 